\title{
Ampoule method fabricated sulfur vacancy-rich N-doped ZnS electrodes for ammonia production in alkaline media
}

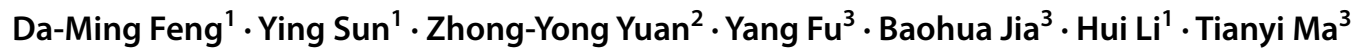

Received: 5 November 2020 / Accepted: 3 April 2021 / Published online: 12 April 2021

(c) The Author(s) 2021

\begin{abstract}
The electrochemical production of green and low-cost ammonia requests the development of high-performance electrocatalysts. In this work, the ampoule method was applied to modulate the surface of the zinc electrode by implanting defects and low-valent active sites. The $\mathrm{N}$-doped $\mathrm{ZnS}$ electrocatalyst was thus generated by sulfurization with thiourea and applied for electrocatalytic nitrogen reduction reaction (ENRR). Given the rich sulfur vacancies and abundant $\mathrm{Zn}-\mathrm{N}$ active sites on the surface, excellent catalytic activity and selectivity were obtained, with an $\mathrm{NH}_{3}$ yield rate of $2.42 \times 10^{-10} \mathrm{~mol} \mathrm{~s}^{-1} \mathrm{~cm}^{-2}$ and a Faradaic efficiency of $7.92 \%$ at $-0.6 \mathrm{~V}$ vs. RHE in $0.1 \mathrm{M} \mathrm{KOH}$ solution. Moreover, the as-synthesized zinc electrode exhibits high stability after five recycling tests and a $24 \mathrm{~h}$ potentiostatic test. The comparison with $\mathrm{Zn}$ foil, non-doping $\mathrm{ZnS} /$ $\mathrm{Zn}$ and recent metal sulfide electrocatalysts further demonstrated advanced catalytic performance of $\mathrm{N} @ \mathrm{ZnS} / \mathrm{Zn}$ for ENRR. By simple synthesis, $\mathrm{S}$ vacancies, and $\mathrm{N}$-doping defects, this promising electrocatalyst would represent a good addition to the arena of transition-metal-based catalysts with superior performance in ENRR.
\end{abstract}

\section{Graphic abstract}

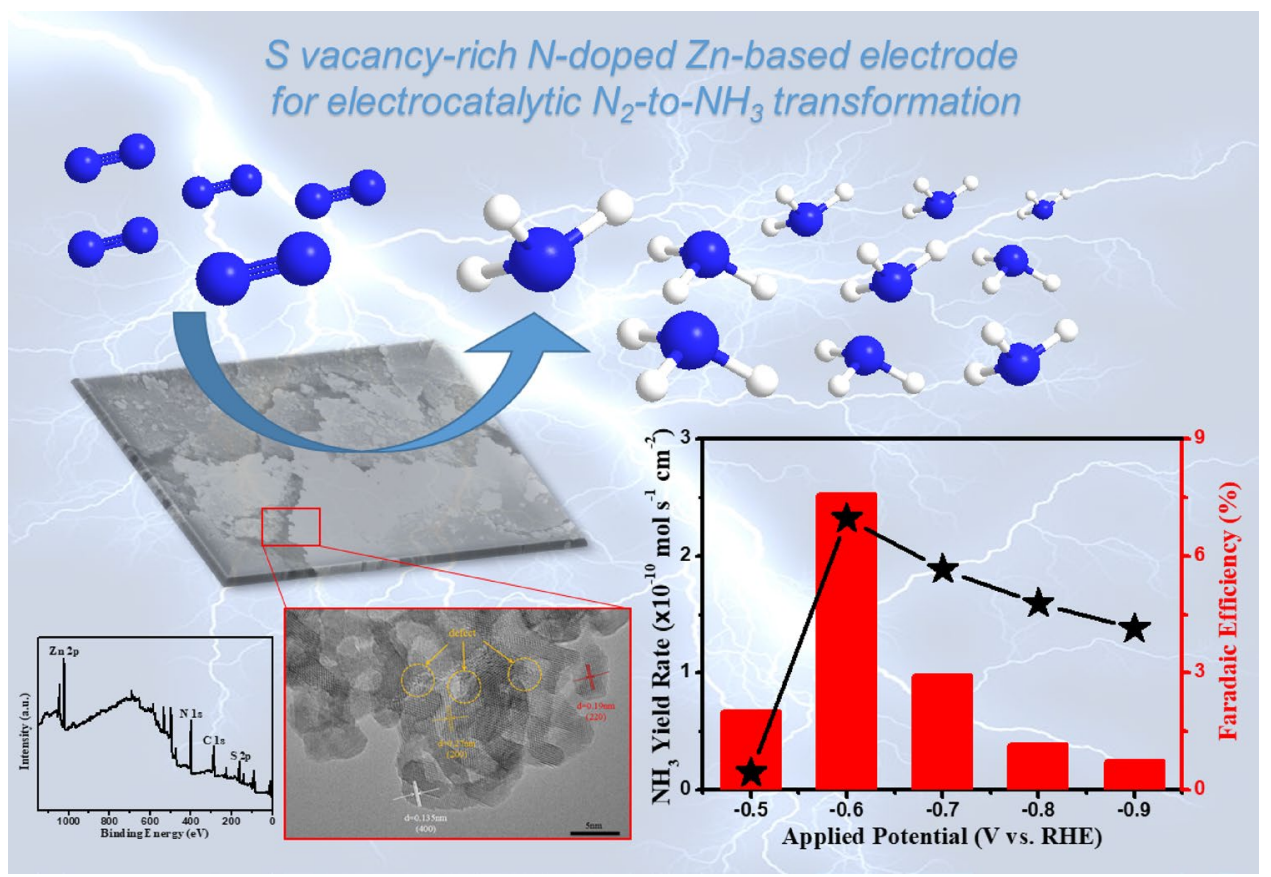

Keywords Ampoule method $\cdot$ Zinc-based electrocatalyst $\cdot$ Sulfur vacancy $\cdot$ Ammonia synthesis

Extended author information available on the last page of the article 


\section{Introduction}

In decades, chemical nitrogen fixation has become a hotspot of chemistry research [1]. It is a sought-after process that converting atmospheric dinitrogen gas into the nitrogen-containing compounds acquired by modern civilization [2]. Nowadays, the utilization of dinitrogen gas is mainly focused on the synthesis of ammonia, a vital industrial raw material [3]. Emerged as one of the promising alternatives to the traditional Haber-Bosch process, electrocatalytic nitrogen reduction reaction (ENRR) has drawn increasing attention. Instead of the high consumption of fossil fuels and massive amounts of greenhouse gas emission, the ENRR provides a clean generation of $\mathrm{NH}_{3}$ in aqueous electrolytes under ambient conditions [4]. However, the reaction efficiency is restricted by the kinetic and thermodynamic features of dinitrogen gas under ambient conditions. And due to the inevitable electrocatalytic hydrogen emission reaction (HER) that took place in the aqueous electrolytes, the development of a practical ENRR technique is still challenging [5].

The past 5 years witnessed numerous metal-based materials that were fabricated and adopted as electrocatalysts for the ENRR process [6, 7]. Regarding the improvement of the catalytic efficiency and selectivity toward ENRR, defect engineering is widely used as an efficient protocol to tune the superficial morphology and band structure of the nano-electrocatalysts, which facilitates the adsorption and activation of the $\mathrm{N}_{2}$ molecule [8]. Therein, using sulfur-containing substances as synthetic precursors for producing metal-based electrocatalysts may originally generate a nitrogenases-mimicking active site for enhancing the ENRR process [9].

As an element in the VI group, sulfur has a relatively weak electronegativity, which determined its diversity of bonding form. For instance, the sulfur reacts with metal elements to form ionic compounds, and shares electrons to bond with itself to form a chain-shaped polysulfide ion $\mathrm{S}_{\mathrm{n}}{ }^{2-}$. Therefore, the structure of metal sulfides tends to be diversified and complicated, which make sulfur a fascinating and promising doping element for functional metal electrocatalysts construction. In addition, it is reasonable to suppose that sulfur defects and vacancies would exhibit great potential in improving the activity of ENRR due to the enhancement of ENRR performance presented by the oxygen vacancies. After theoretical study and experiments, the $\mathrm{MoS}_{2}$ catalysts provided a distinctive electrocatalytic effect in producing ammonia from $\mathrm{N}_{2}$ gas in an aqueous solution [10-12]. Furthermore, the N-doped $\mathrm{MoS}_{2}$ nanoflowers presented enhanced catalytic performance due to rich $\mathrm{S}$ vacancies and Mo-N active sites [13]. Besides, with the aid of abundance $\mathrm{S}$ vacancies, $\mathrm{ZrS}_{2}$ nanofibers were also proven as a stable and active catalyst for ambient electrochemical $\mathrm{N}_{2}$-to- $\mathrm{NH}_{3}$ conversion with excellent selectivity [14]. Apart from early stage transition metals, iron-series metals were adopted as robust alternatives in ENRR by diverse modifications. Through solvothermal method and plasma synthesis, the $\mathrm{Fe}_{3} \mathrm{~S}_{4}$ nanosheet [15] and surface-sulfurized Fe foam [16] both exhibited outstanding catalytic performance due to the low valence metallic site and $\mathrm{S}$ vacancies with suitable $\mathrm{Fe}-\mathrm{Fe}$ distance. Because of the various bonding modes and enhanced conductivity, cobalt-based composite materials, $\mathrm{CoS}_{2} @ \mathrm{NC}$ [17], $\mathrm{CoS}_{2}-\mathrm{N} / \mathrm{S}-\mathrm{C}$ [18] and C@CoS@ $\mathrm{TiO}_{2}$ [19], were certified as good candidates for ENRR with the gratifying $\mathrm{NH}_{3}$ yields $[20,21]$. However, most of the sulfide electrodes were obtained in aqueous conditions, which displayed an inferior synthetic efficiency due to the insolubility issue of metal sulfides. And the complicated synthetic routes pose a significant barrier to the practical use of metal sulfides in ENRR.

On the other hand, the controllable synthesis of electrocatalysts for various electrochemical reactions is a stateof-art technological challenge in both electrochemistry and material science [22]. Among all of the existing synthetic processes, the ampoule method owns superpassingly versatility in preparing self-standing electrode materials, including alloys, nitrides, phosphides, chalcogenides, and halides. Made from silica, quartz, and corrosion-resistant niobium and tantalum, the ampoules can be simply selfdesigned according to the requirement of various materials synthetic processes. Meanwhile, the solid or liquid reactants can be loaded inside the ampoule under evacuated or inert gas conditions before sealing the open end. After that, the heat-up step is always implemented in a furnace with hetero- or homogeneous applying temperature over a wide range. By such manipulations, the reaction conditions and atmosphere are confined, sequentially eliminating the environmental impact and thus realizing the controllable synthesis. These days, the surface-modified transition-metal foil materials generated from the ampoule method have already been applied to various electrocatalytic reactions [23-27].

With our ongoing interests in the ampoule methods for synthesizing catalytic materials and exploration of electrocatalytic ENRR, [28-30] herein, we propose the N@ZnS/ $\mathrm{Zn}$ materials fabricated through the facile ampoule method that enables the electrochemical synthesis of ammonia in ambient conditions. The $\mathrm{S}$ vacancies and $\mathrm{Zn}-\mathrm{N}$ activate sites are speculated to facilitate the adsorption of the $\mathrm{N}_{2}$ and reduction process. The adopted alkaline electrolytes and potassium cations present enough HER inhibition, which allows efficient synthesis of $\mathrm{NH}_{3}$. 


\section{Experimental section}

\section{Chemicals}

Zinc foil (99.95\% trace metals basis, thickness $0.1 \mathrm{~mm}$ ) was purchased from Sigma-Aldrich. Potassium sodium tartrate, thiourea $\left(\mathrm{CS}\left(\mathrm{NH}_{2}\right)_{2}\right)$, sulfur power (re-sublimation), hydrochloric acid ( $\mathrm{HCl}, 36-38 \%)$, and hydrogen peroxide $\left(\mathrm{H}_{2} \mathrm{O}_{2}\right.$, $30 \%$ ) were purchased from Tianjin Yongda Chemical Reagent Co., Ltd. Potassium hydroxide (KOH) and Nessler's reagent were purchased from Tianjin Damao Chemical Reagent Co., Ltd. Nitrogen $\left(\mathrm{N}_{2}, 99.999 \%\right)$ and argon (Ar, 99.999\%) were purchased from Shenyang Zhaote Special Gas Co., Ltd. All the chemicals were used without further purification.

\section{Zinc-based electrode synthesis}

The zinc-based catalytic electrodes were synthesized through the ampoule method. In the beginning, the zinc foil was polished and cleaned with anhydrate ethanol, acetone, $1 \mathrm{M} \mathrm{HCl}$, and Milli-Q water for $5 \mathrm{~min}$ in sequence. After cutting into pieces $(180 \mathrm{mg}, 2 \mathrm{~cm} \times 0.4 \mathrm{~cm} \times 0.01 \mathrm{~cm}$, length $\times$ width $\times$ height), the pretreated zinc foils were sealed with sulfurization reagents ampoule under vacuum and calcinated at $400{ }^{\circ} \mathrm{C}$ for $5 \mathrm{~h}$. The heating rate was $5{ }^{\circ} \mathrm{C} / \mathrm{min}$ and the cooling process took place naturally. During this process, the $\mathrm{Zn}$ atoms of the foil were sulfurized by sulfur atom vapor under pressure, leading to free-standing electrodes possessing $\mathrm{ZnS}$ species on the surface. The material that sulfurized with thiourea and sulfur power is named $\mathrm{N} @ \mathrm{ZnS} / \mathrm{Zn}$ and $\mathrm{ZnS} / \mathrm{Zn}$, respectively.

\section{Instruments and characterization}

The X-ray diffraction (XRD) patterns were obtained on a Bruker (Germany) D8 Advance diffractometer with $\mathrm{Cu} \mathrm{K} \alpha$ radiation in the range of $20^{\circ}-80^{\circ}(2 \theta)$. The scanning electron microscope (SEM) images and elemental mapping images were performed in a Hitachi SU8000. Transmission electron microscope (TEM) images were obtained from a JEOL JEM-2100 at an acceleration voltage of $200 \mathrm{kV}$. X-ray photoelectron spectroscopy (XPS) measurement was carried out on an ESCALAB Mk II (Vacuum generators) spectrometer with an Al K X-ray source ( $240 \mathrm{~W})$.

\section{Electrochemical tests}

In general, the ENRR experiments were conducted in a twocompartment electrolysis cell that separated by the Nafion 117 membrane under ambient condition. The membrane was protonated by first boiling in ultrapure water for $1 \mathrm{~h}$ and treating in $\mathrm{H}_{2} \mathrm{O}_{2}(5 \%)$ aqueous solution at $80{ }^{\circ} \mathrm{C}$ for another $1 \mathrm{~h}$ in sequence. The membrane was then treated in $0.5 \mathrm{~m} \mathrm{H}_{2} \mathrm{SO}_{4}$ for $3 \mathrm{~h}$ at $80^{\circ} \mathrm{C}$ and finally stored in ultrapure water overnight. The electrochemical measurements were conducted using CHI 760 E electrochemical workstation (CH Instruments, Inc., USA) with a three-electrode configuration. Before proceeding with electrocatalytic tests, the synthesized materials were ultrasonicated Milli$\mathrm{Q}$ water for $30 \mathrm{~min}$ and activated by electrolysis with the setups of ENRR tests in Ar-saturated $0.1 \mathrm{M} \mathrm{KOH}$ electrolyte at $-0.7 \mathrm{~V}$ vs RHE for $48 \mathrm{~h}$. The as-prepared and activated zinc sulfide materials were used as the working electrode, while the graphite rod electrode and $\mathrm{Ag} / \mathrm{AgCl}$ electrode $(3.5 \mathrm{M} \mathrm{KCl}$ electrolyte) were adopted as the counter and reference electrode, respectively. Unless otherwise specified, the $0.1 \mathrm{M} \mathrm{KOH}$ solution $(\mathrm{pH}=13)$ was adopted as the electrolyte in the linear sweep voltammetry (LSV) and chronoamperometry tests. The measured potentials vs. $\mathrm{Ag} / \mathrm{AgCl}$ were converted to a reversible hydrogen electrode (RHE) scale according to the Nernst equation $\left(E_{\mathrm{RHE}}=E_{\mathrm{Ag} / \mathrm{AgCl}}+0.059 \mathrm{pH}+0.205=E_{\mathrm{Ag} / \mathrm{AgCl}}+0.972\right)$. Also, the outlet gas was introduced to an acid bottle with $5 \mathrm{~mL}$ of $2 \mathrm{M} \mathrm{HCl}$ for wet scrubbing to collect the possible leaking ammonia.

\section{Determination of products}

The concentrations of the synthesized $\mathrm{NH}_{3}$ are detected by ammonia-sensitive electrode measurement and colorimetric method using Nessler reagent.

For the ammonia-sensitive electrode measurement, $5 \mathrm{~mL}$ of a solution of electrolyte or five-time diluted tail gas absorber was mixed with $5 \mathrm{~mL} 1 \mathrm{M} \mathrm{KOH}$ solution and $0.2 \mathrm{~mL}$ low-level ammonia $\mathrm{pH}$-adjusting ISA solution (Thermofisher). After stirring, the voltage was obtained using the ammonia-sensitive selecting electrode (Thermofisher) when stable. The standard curve is constructed by measuring a series of voltage for the reference solutions with $0.1 \mathrm{M}$ $\mathrm{KOH}$ and different $\mathrm{NH}_{4} \mathrm{Cl}$ concentrations $\left(0.8 \mu \mathrm{g} \mathrm{mL}{ }^{-1}\right.$, $\left.0.4 \mu \mathrm{g} \mathrm{mL}^{-1}, 0.2 \mu \mathrm{g} \mathrm{mL}^{-1}, 0.1 \mu \mathrm{g} \mathrm{mL}^{-1}\right)$.

For the colorimetric method, $25 \mathrm{~mL}$ solution of electrolyte and five-time diluted tail gas absorber was mixed with $0.5 \mathrm{~mL} 50 \%$ potassium sodium tartrate solution. Then, $0.75 \mathrm{~mL}$ Nessler's reagent and the mixture were allowed still for $10 \mathrm{~min}$. The absorbance was tested by UV-Vis spectrometer (Shimadzu UV-2600) under light at $420 \mathrm{~nm}$ wavelength with deionized water as a reference. The standard curve is constructed by measuring a series of absorbances for the reference solutions with $0.1 \mathrm{M} \mathrm{KOH}$ and different $\mathrm{NH}_{4} \mathrm{Cl}$ concentrations $\left(2.0 \mu \mathrm{g} \mathrm{mL}^{-1}, 1.6 \mu \mathrm{g} \mathrm{mL}^{-1}, 1.2 \mu \mathrm{g} \mathrm{mL}^{-1}\right.$, $0.8 \mu \mathrm{g} \mathrm{mL}^{-1}, 0.4 \mu \mathrm{g} \mathrm{mL}^{-1}, 0.2 \mu \mathrm{g} \mathrm{mL}^{-1}, 0.1 \mu \mathrm{g} \mathrm{mL}^{-1}$, 
$\left.0 \mu \mathrm{g} \mathrm{mL}^{-1}\right)$. The background is corrected by a blank solution with $0.1 \mathrm{M} \mathrm{KOH}$ and Nessler's reagent.

The concentration of hydrazine in the electrolyte was evaluated via Watt and Chrisp method. The chromogenic agent was produced by mixing para-(dimethylamino) benzaldehyde $(2 \mathrm{~g})$, concentrated $\mathrm{HCl}(10 \mathrm{~mL})$, and ethanol $(100 \mathrm{~mL})$. After blending with the agent, the resulting electrolytes were detected by measuring the absorbance at $455 \mathrm{~nm}$.

\section{Results and discussion}

\section{Synthesis and characterization}

The synthesis of $\mathrm{N} @ \mathrm{ZnS} / \mathrm{Zn}$ was following the typical process of the ampoule method. At first, the electrode shape zinc foil and thiourea were sealed in an ampoule bottle under a vacuum line. Then the sulfurization took place when putting the sealed ampoule bottle in the tube furnace under $400{ }^{\circ} \mathrm{C}$ for $5 \mathrm{~h}$, generating surface sulfurized $\mathrm{N} @ \mathrm{ZnS} / \mathrm{Zn}$ material (Fig. 1a). Before characterizing and applying in the electrochemical tests, the activation of the as-prepared N@
$\mathrm{ZnS} / \mathrm{Zn}$ was conducted to get rid of the impurity adsorbed on the surface as well as the nitrogen-containing species.

The morphology and microstructure of as-prepared N@ $\mathrm{ZnS} / \mathrm{Zn}$ are examined by scanning electron microscopy (SEM). The rough surface of the materials is presented in Fig. 1b, with particle size between 50 and $100 \mathrm{~nm}$ (Fig. 1d). To obtain more evidence for the effectiveness of the material, the high-resolution transmitting electron microscopy (HRTEM) is adopted and the picture is shown in Fig. 1c. Moreover, plenty of crystal phases and abundant surface defects can be observed at $5 \mathrm{~nm}$ resolution (Fig. 1e), further proving the stability and robustness of the electrode material. Meanwhile, the energy dispersive spectroscopy (EDS) was applied to compare the element ratio of the non-activated N@ZnS/Zn with activated ones After the calculation and approximation, the $\mathrm{Zn}: \mathrm{S}: \mathrm{N}$ ratio is altered from 6: 3: 2.7 to 6: 4: 1 (Figure $S 1$ and $S 2$ ). The remaining $N$ atoms on the surface indicate the formation of $\mathrm{Zn}-\mathrm{N}$ bonds, which is one of the reasons for the electrode with extraordinary performance in ENRR (Figure S1). And the EDS-mapping exhibited a homogeneous distribution for the $\mathrm{Zn}, \mathrm{S}$, and $\mathrm{N}$ atoms (Fig. 1d).

The X-ray diffraction (XRD) patterns to the surface of asprepared and activated N@ZnS/Zn are presented in Fig. 2.

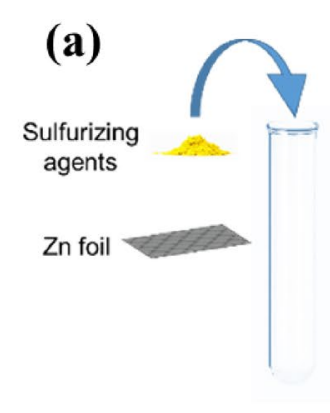

Loading

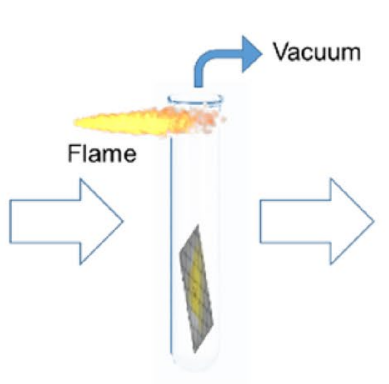

Seal

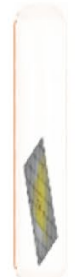

Pyrolysis

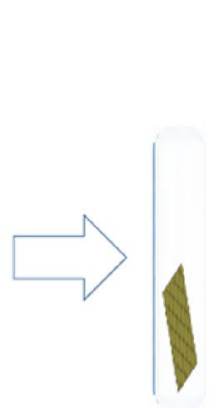

Cooling down

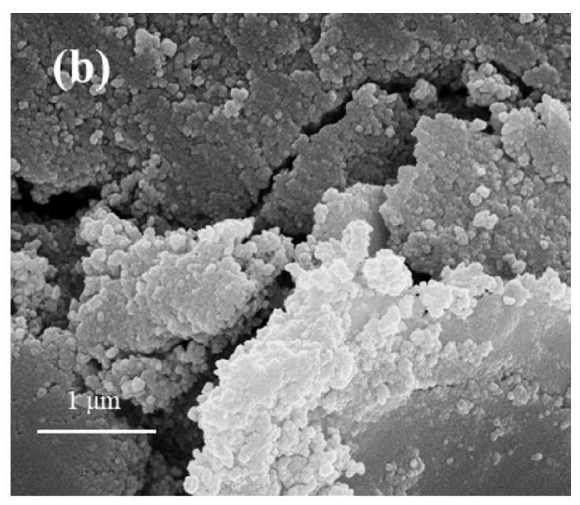

$\mathrm{Zn}$

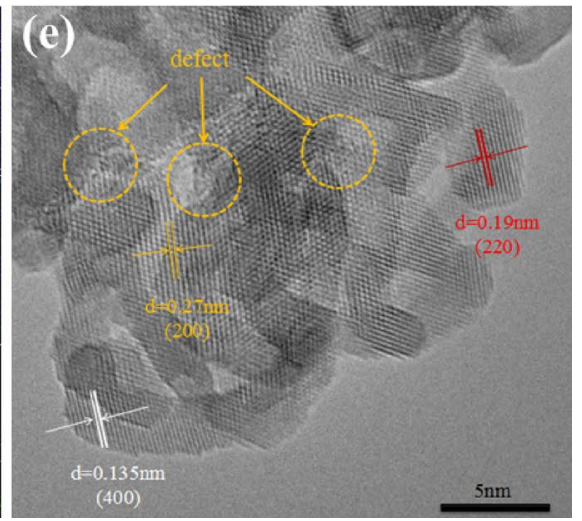

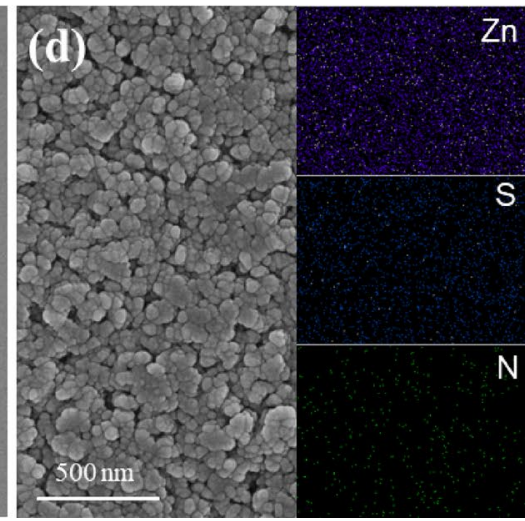

Zn; inset: SEM-EDS elemental mapping images of Zn, S and N. e

Fig. 1 Synthesis and characterization of catalysts. a Synthetic route for zinc sulfide materials using ampoule method. b SEM image of N@ZnS/Zn. c TEM image of N@ZnS/Zn. d SEM image of N@ZnS/
HR-TEM image of N@ZnS/Zn with surface defects and cell spacing presented 


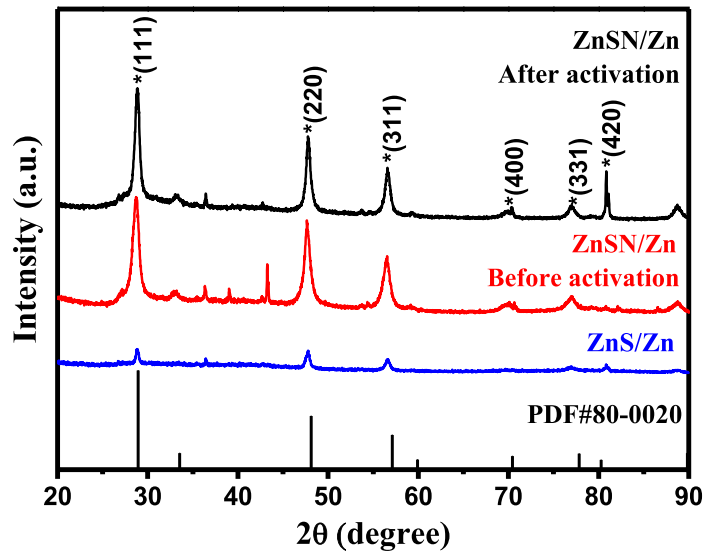

Fig. 2 XRD patterns of $\mathrm{N} @ \mathrm{ZnS} / \mathrm{Zn}$ and ZnS/Zn materials

According to the standard PDF \# 80-0200, the diffraction peaks at $28.5^{\circ}, 47.5^{\circ}, 56.3^{\circ}, 69.4^{\circ}, 76.6^{\circ}$, and $81.2^{\circ}$ are the character peaks attributing to the (111), (220), (311), (400), (331), (420) planes of the zinc sulfide crystal, which implies the sphalerite $\mathrm{ZnS}$ species existing on the material surface. The relatively broad peaks and the rough baseline demonstrate the amorphous nature of the material surface. In addition, the XRD pattern of non-activated $\mathrm{N} @ \mathrm{ZnS} / \mathrm{Zn}$ material is also demonstrated in Fig. 2. With more peaks of impurities presenting in the diagram, the activation process is therefore necessary. To obtain more details of the surface composition and structure, the $\mathrm{ZnS} / \mathrm{Zn}$ with sulfur powder as sulfurizing agents by the ampoule method is also synthesized. The XRD pattern of $\mathrm{ZnS} / \mathrm{Zn}$ shows the peaks at $28.5^{\circ}$, $47.5^{\circ}, 56.3^{\circ}, 76.6^{\circ}$, and $81.2^{\circ}$ belong to the $\mathrm{ZnS}$ species, within which the lower peaks may ascribe to the moderated crystallinity.

The full-range X-ray photoelectron spectroscopy (XPS) spectra of activated N@ZnS/Zn is shown in Fig. 3a, which demonstrated the presence of the elements $\mathrm{Zn}, \mathrm{S}$, and $\mathrm{N}$. The measured binding energies are in-line with those reported in the literature [31]. In particular, the binding energy of $\mathrm{Zn}$ $2 p_{3 / 2}$ and $\mathrm{Zn} 2 p_{1 / 2}$ is located at $1022.9 \mathrm{eV}$ and $1045.9 \mathrm{eV}$, respectively (Fig. $3 \mathrm{~b}$ ). The difference between the two core level components of $\mathrm{Zn} 2 p_{3 / 2}$ and $\mathrm{Zn} 2 p_{1 / 2}$ is approximately $23 \mathrm{eV}$, indicating the bivalent state of $\mathrm{Zn}$. Moreover, the fitting of the XPS spectrum sulfur $\mathrm{S} 2 p$ peaks exhibits the main sulfur species on the surface of $\mathrm{N} @ \mathrm{ZnS} / \mathrm{Zn}$, which can be divided into two main characteristic peaks at $161.6 \mathrm{eV}$
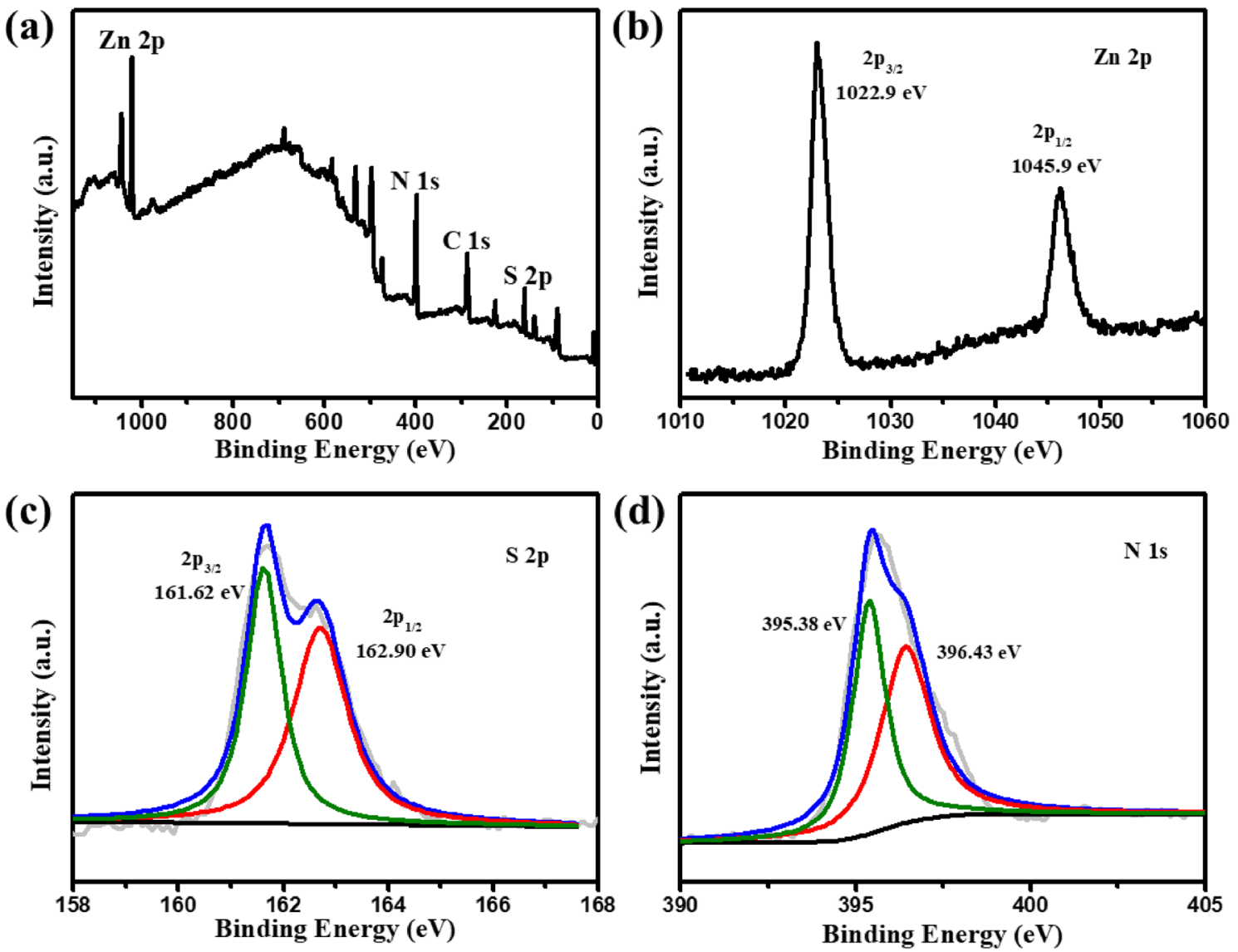

Fig. 3 XPS spectra of the N@ZnS/Zn samples: a Full spectrum; b Zn $2 p$ spectrum; c S $2 p$ spectrum; d N 1 s spectrum 
and $162.9 \mathrm{eV}$, ascribed to the $\mathrm{S} 2 p_{3 / 2}$ and $\mathrm{S} 2 p_{1 / 2}$ respectively, in a good agreement with the energy of the S-Zn bond (Fig. 3c) [31]. The existence of polysulfides, one of the primary reasons for emerged $\mathrm{S}$ vacancies, were speculated based on the $1.3 \mathrm{eV}$ difference of the binding energies. Meanwhile, the presence of the $\mathrm{N} 1 \mathrm{~s}$ characteristic peak located at $395.38 \mathrm{eV}$ and $396.43 \mathrm{eV}$ reveals the existence of the $\mathrm{Zn}-\mathrm{N}$ bond according to the literature (Fig. 3d) [32]. It is noteworthy that the residual nitrogen on the surface of $\mathrm{N} @ \mathrm{ZnS} / \mathrm{Zn}$ after the activation would not be reduced into ammonia due to the binding.

The results from the above material characterizations demonstrate that the surface modification of $\mathrm{Zn}$ foil by sulfurization with thiourea through the ampoule method provides stable amorphous $\mathrm{ZnS}$ with abundant $\mathrm{S}$ vacancies and $\mathrm{Zn}-\mathrm{N}$ binding active sites promising for electrocatalysis for ENRR.

\section{Electrocatalytic ENRR performances}

To evaluate the electrocatalytic ENRR efficiency of N@ $\mathrm{ZnS} / \mathrm{Zn}$ under ambient conditions, several electrochemical tests were performed in $\mathrm{N}_{2}$-saturated $0.1 \mathrm{M} \mathrm{KOH}$

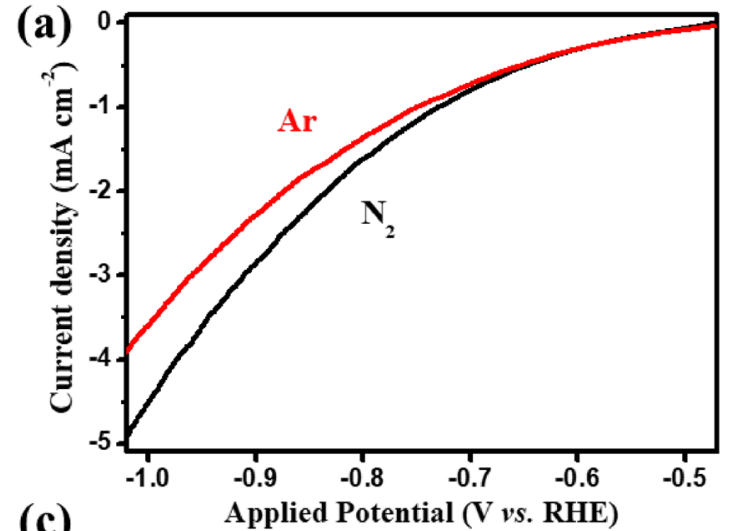

(c)

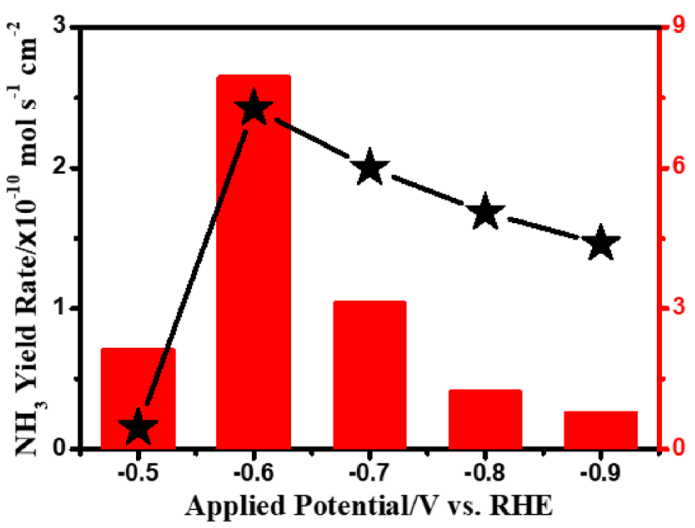

Fig. 4 Electrocatalytic performance of $\mathrm{N} @ \mathrm{ZnS} / \mathrm{Zn}$ electrode for ENRR. a LSV in $\mathrm{N}_{2}$ - and Ar-saturated electrolytes; $\mathbf{b}$ It-curves from chronoamperometry tests under different potentials; c Calculated FE electrolyte. The divided cells were used to carry out the experiments, and a proton conductive cation exchange membrane (Nafion 117) was adopted to separate the cathode and anode chamber. Ahead of the electrochemical tests, the $2 \mathrm{~h}$ electrolysis of $\mathrm{N}_{2}$-saturated electrolytes and Ar-saturated electrolytes with the working electrode was conducted at open circuit potential and $-0.7 \mathrm{~V}$ vs RHE, respectively. After that, the resulting solutions were examined by Nessler's reagent with no obvious $\mathrm{NH}_{4}{ }^{+}$detection, thus proving that there are no ammonia-like impurities in the feeding gas and reaction environment.

At first, we explored the performances of the $\mathrm{N} @ \mathrm{ZnS} /$ $\mathrm{Zn}$ electrodes in ENRR through the comparison of the linear sweep voltammetry (LSV) curves under Ar- and $\mathrm{N}_{2}$-saturated electrolytes (Fig. 4a). The increasing current density along with the increasing potentials is due to the competing hydrogen reduction reaction (HER) that is enhanced gradually in both LSV tests. A higher current density in $\mathrm{N}_{2}$-saturated electrolytes was then observed compare to the Ar-saturated ones when the applied potential was more negative than $-0.55 \mathrm{~V}$ vs RHE, which indicates the electrosynthesis of ammonia proceeding in the $\mathrm{N}_{2}$-saturated cell. This phenomenon further proves the
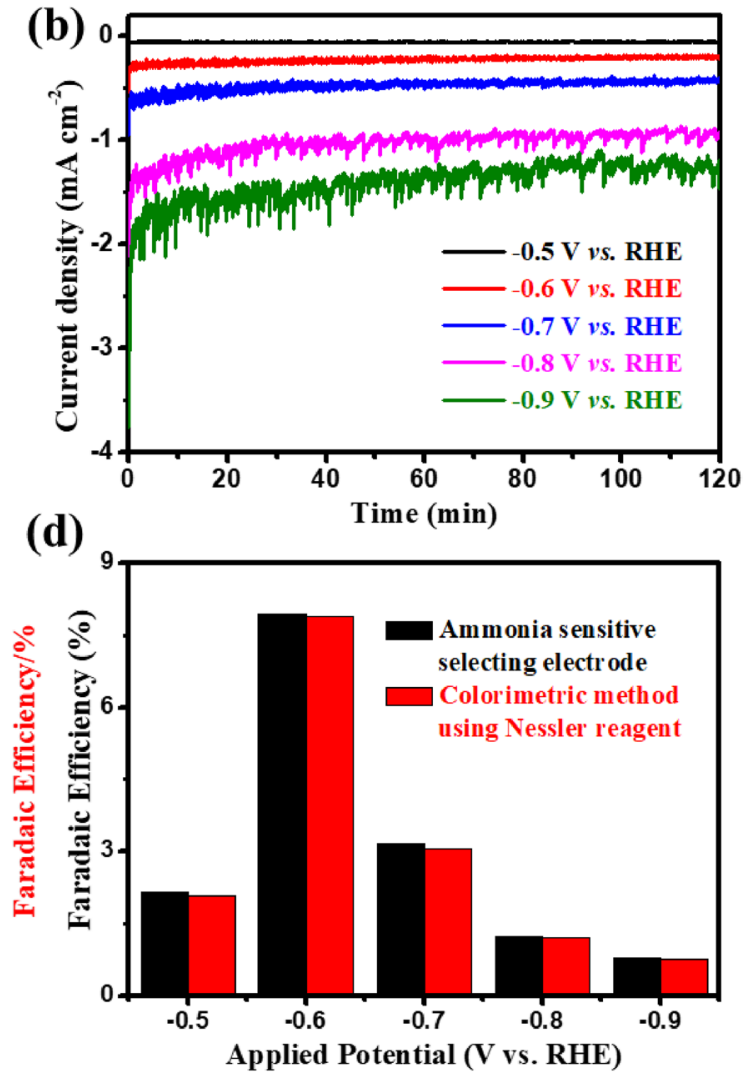

and $\mathrm{NH}_{3}$ yield rate values at controlled potentials; $\mathbf{d}$ Comparison of the ammonia-sensitive selecting electrode and Nessler reagent-based colorimetric method for the quantitative analysis of FE values 
effectiveness of the $\mathrm{N} @ \mathrm{ZnS} / \mathrm{Zn}$ electrode in the electrocatalytic ENRR process.

After confirming the validity of the working electrode in ENRR, several chronoamperometry tests were conducted in $\mathrm{N}_{2}$-saturated $0.1 \mathrm{M} \mathrm{KOH}$ solution for $2 \mathrm{~h}$ each under controlled potentials $(-0.5 \mathrm{~V},-0.6 \mathrm{~V},-0.7 \mathrm{~V},-0.8 \mathrm{~V},-0.9 \mathrm{~V}$ vs RHE) to further evaluate the catalytic performance of $\mathrm{N} @$ $\mathrm{ZnS} / \mathrm{Zn}$ material. The It-curves are shown in Fig. 4b. As the $\mathrm{pH}$ value of the electrolyte is higher than the $\mathrm{pKa}$ value of ammonia, an acidic gas absorber was also installed on the electrochemical cell, in the case of ammonia gas emitting.

After the chronoamperometry tests, the corresponding $\mathrm{NH}_{3}$ concentrations of the electrolytes, as well as solutions in the absorber, were all measured by spectroscopy using Nessler's reagent and ammonia-sensitive selecting electrode methods (see more details in the Experimental section and Figures S3, S4 in supporting information, which shows the calibration curves for confirmation of ammonia concentration). Given that $\mathrm{N}_{2} \mathrm{H}_{4}$ is a possible by-product during the electrolysis, the colorimetric method was also employed to examine the existence of $\mathrm{N}_{2} \mathrm{H}_{4}$ for the electrolytes from the above-mentioned chronoamperometry tests. Since no $\mathrm{N}_{2} \mathrm{H}_{4}$ was detected in solutions, the good selectivity for the ENRR was thus verified. After the calculations, the Faradic efficiency (FE) and the yield rate of ammonia for all the chronoamperometry tests were obtained and listed in Fig. 4c. As shown, the highest FE, 7.92\%, the highest yield rate of $\mathrm{NH}_{3}, 2.42 \times 10^{-10} \mathrm{~mol} \mathrm{~s}^{-1} \mathrm{~cm}^{-2}$, were obtained with onset potential at $-0.6 \mathrm{~V}$ vs RHE. Consistent with the observation in the LSV curves, a gradual decrease of both FE and yield rate can be observed with the more negative onset potentials, which might ascribe to the dominant role of competing for HER process at higher potentials. It is noteworthy that the yield rate of $\mathrm{NH}_{3}$ was remaining in the range of $1.3-2.3 \mathrm{~mol} \mathrm{~s}^{-1} \mathrm{~cm}^{-2}$, suggesting the steady catalytic efficiency of the electrode in alkaline solution under ambient conditions.

As a similar amount of ammonia generating at each potential, the higher and higher electricity consumed reduces the efficiency of this electrocatalytic $\mathrm{N}_{2}$ fixation. This also explains the increasing current density yet decreasing FE at high potentials observed in the It-curves. In the meantime, the validity and reliability of the $\mathrm{NH}_{3}$ concentrations that measured with the ammonia-sensitive selecting electrode as well as the colorimetric method using Nessler reagent were verified with close FE values (Fig. 4d).

With the evaluation of electrocatalytic performance for ENRR in hand, the long-term stability and robustness of the $\mathrm{N} @ \mathrm{ZnS} / \mathrm{Zn}$ electrocatalyst were then examined. At first, a 24 h durability test was conducted at $-0.7 \mathrm{~V}$ vs RHE in alkaline electrolyte, and the It-curve was shown in Fig. 5a. The few fluctuations along the current density curve and a final $2.86 \% \mathrm{FE}$ value illustrated the consistent durability of the $\mathrm{N} @ \mathrm{ZnS} / \mathrm{Zn}$ electrocatalyst over a long time. Furthermore, to estimate the catalytic effectiveness of the N@ZnS/Zn electrode, five times parallel tests for $2 \mathrm{~h}$ each were also carried out at $-0.6 \mathrm{~V}$ vs RHE. After examining the ammonia concentration by the colorimetric method, the $\mathrm{NH}_{3}$ yield rates and $\mathrm{FE}$ values were calculated and presented in Fig. 5b. The long-acting of the $\mathrm{N} @ \mathrm{ZnS} / \mathrm{Zn}$ electrocatalyst was thus exhibited with almost no decrease FE for the electrochemical generation of ammonia.

To gain more insight into the relationship between structure and function, the comparing of the catalytic performance in the electrocatalytic ENRR process was made through conducting chronoamperometry measurements using N@ZnS/Zn, ZnS/Zn, and Zn foil as the working electrode at $-0.6 \mathrm{~V}$ vs RHE in alkaline electrolytes. The related $\mathrm{NH}_{3}$ yield rates and $\mathrm{FE}$ values were listed and compared in Fig. 5c. As expected, the $\mathrm{Zn}$ foil exhibited no effect for electrocatalytic ENRR, while $\mathrm{ZnS} / \mathrm{Zn}$ electrocatalyst mediated the $\mathrm{NH}_{3}$ synthesis with $4.11 \% \mathrm{FE}$ and $0.24 \times 10^{-10} \mathrm{~mol} \mathrm{~s}^{-1} \mathrm{~cm}^{-2}$ yield rate, almost one-tenth of the performance with $\mathrm{N}$-doped. Considering the observation from XRD patterns, the attenuated electrocatalytic performance of $\mathrm{ZnS} / \mathrm{Zn}$ material may attribute to the less formation of $S$ vacancies and active sites on the surface caused by the lack of $\mathrm{N}$ dopant. In other words, the $\mathrm{N}$ doping not only plays a vital role in generating surface defects but also improve the band structure of the material, which would significantly improve the catalytic performance in the ENRR process.

Furthermore, another comparison was also held to evaluate the influence of the $\mathrm{pH}$ value of the electrolyte. As the $\mathrm{Zn}$-based electrode is very reactive to an acidic solution, a neutral solution, $0.1 \mathrm{M} \mathrm{K}_{2} \mathrm{SO}_{4}$ electrolyte, was used in potentiostatistic tests at $-0.6 \mathrm{~V}$ vs RHE with $\mathrm{N} @ \mathrm{ZnS} / \mathrm{Zn}$ as the working electrode with $\mathrm{FE}$ value and $\mathrm{NH}_{3}$ yield rate presented also in Fig. 5c. In contrast to alkaline electrolytes, neutral solution displayed a moderated effect in $\mathrm{N}_{2}$ gas fixation, which ascribe to less HER inhibition under the neutral conditions. Intriguingly, the appearance of these demonstrated that the possible vacancy filled by $\mathrm{OH}^{-}$rather than $\mathrm{N}_{2}$ from the alkaline electrolytes did not impede the electrosynthesis of $\mathrm{NH}_{3}$ by $\mathrm{N} @ \mathrm{ZnS} / \mathrm{Zn}$ catalyzed.

Therefore, the formation of $\mathrm{NH}_{3}$ is plausibly triggered by the simultaneous adsorption and reduction of $\mathrm{N}_{2}$ and $\mathrm{H}_{2} \mathrm{O}$ molecules. The $\mathrm{N}-\mathrm{N}$ bond is further weakened by the back-donation of zinc electrons to $* \pi$ orbital with the aid of $e$-supply from heteroatoms, sulfur and nitrogen. Furthermore, an integrated reaction between the activated intermediates achieves the generation of $\mathrm{N}-\mathrm{H}$ bonds and the cleavage of the $\mathrm{N}-\mathrm{N}$ bond. After the transmitting of electrons and coupling with hydrogens, the final $\mathrm{NH}_{3}$ molecule desorbs and diffuses into the bulk electrolyte.

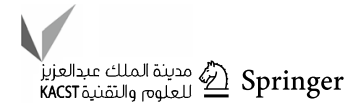


(a)

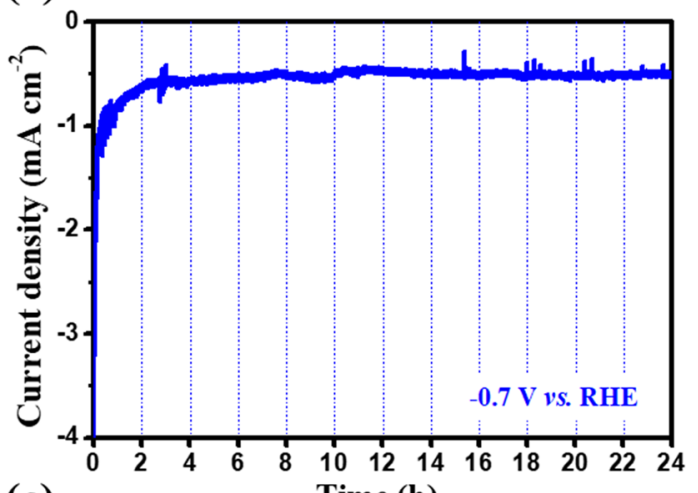

(c)

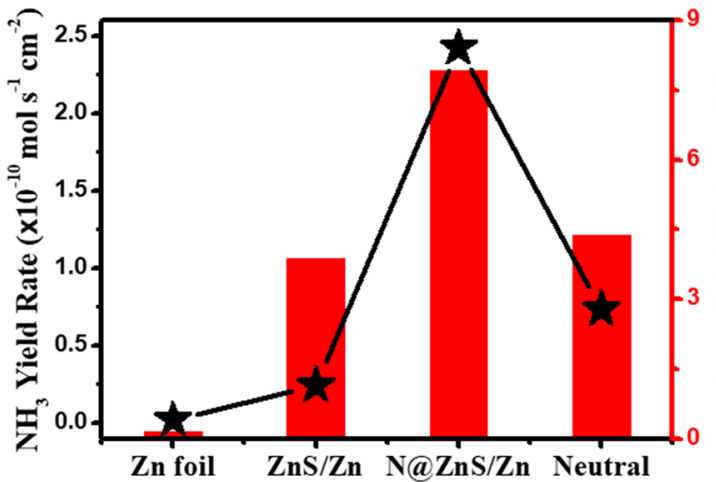

Fig. 5 a Time-dependent current density curve for $\mathrm{N} @ \mathrm{ZnS} / \mathrm{Zn}$ at $-0.7 \mathrm{~V}$ vs RHE for $24 \mathrm{~h}$. b 5 times repeating ENRR at $-0.6 \mathrm{~V}$ vs RHE; c Comparison FE and yield rate values of $\mathrm{Zn}$ foil, ZnS/Zn, N@

Additionally, regarding onset potentials and the FE values of electrochemical $\mathrm{N}_{2}$-to- $\mathrm{NH}_{3}$ transformation, several selected recent works using metal sulfide electrocatalysts were compared graphically with $\mathrm{N} @ \mathrm{ZnS} / \mathrm{Zn}$ in Fig. 5d (more details in Table S1). In the diagram, the relatively superior electrocatalytic performance of $\mathrm{N} @ \mathrm{ZnS} / \mathrm{Zn}$ was shown. In consideration of its low-cost and simple generation protocol, such a durable and robust electrocatalyst is very promising in the practical industrial use for green synthesis of $\mathrm{NH}_{3}$.

\section{Conclusion}

In conclusion, we have developed a novel $\mathrm{N}$-doped zinc sulfide material through the facile ampoule method. The surface components and morphology of the material were examined through various characteristic techniques. Due to the rich $\mathrm{S}$ vacancies and abundant $\mathrm{Zn}-\mathrm{N}$ activate sites, the as-fabricated $\mathrm{N} @ \mathrm{ZnS} / \mathrm{Zn}$ enables the extraordinary electrocatalytic performance for the ENRR process in alkaline electrolytes under ambient conditions. As the (b)

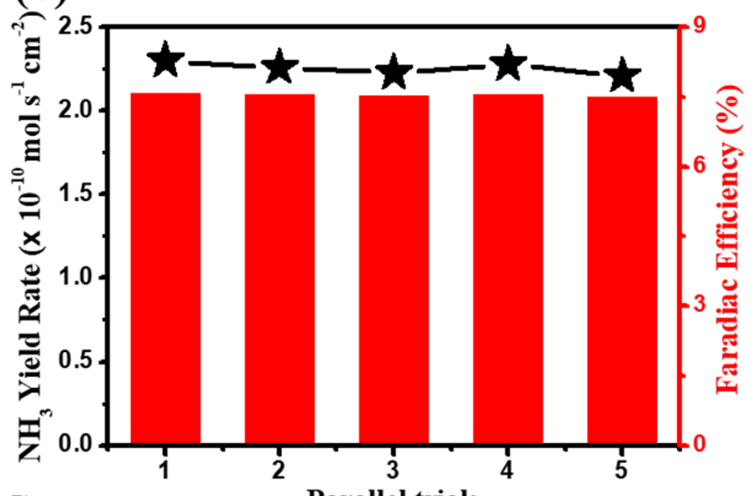

(d)

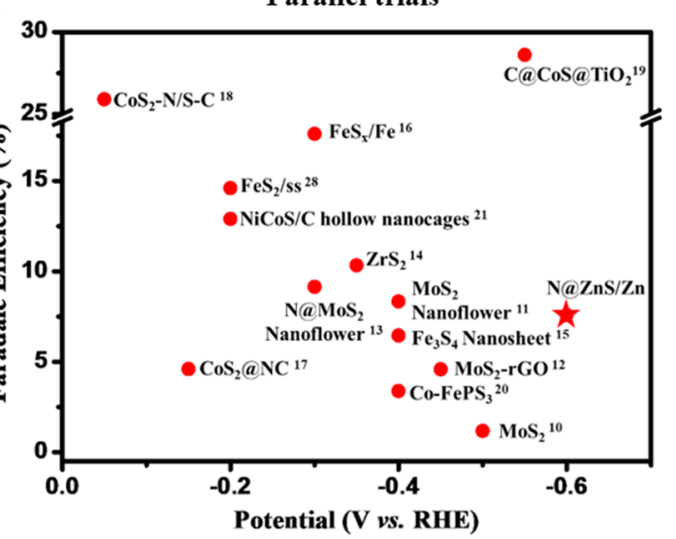

$\mathrm{ZnS} / \mathrm{Zn}$ in alkaline electrolytes, and $\mathrm{N} @ \mathrm{ZnS} / \mathrm{Zn}$ in neutral electrolytes for ENRR; $\mathbf{d}$ Comparison of the performance for ENRR with selected recently reported sulfide electrocatalysts

solemn product, the $\mathrm{NH}_{3}$ product was obtained at a yield rate of $2.42 \times 10^{-10} \mathrm{~mol} \mathrm{~s}^{-1} \mathrm{~cm}^{-2}$ and an FE of $7.92 \%$ at $-0.6 \mathrm{~V}$ vs RHE. The N-doping, surface defects, and the alkaline electrolyte are indispensable factors for the achievement of high electrocatalytic ENRR performance. In the end, the simple controllable synthesis of the electrocatalysts, as well as their long-term stability and catalytic activity, suggest a promising application in the practical industrial use of the functionalized zinc electrode for artificial $\mathrm{N}_{2}$ fixation.

Supplementary Information The online version contains supplementary material available at https://doi.org/10.1007/s40243-021-00193-x.

Acknowledgements This work was supported by National Natural Science Foundation of China (No. 52071171), Liaoning Revitalization Talents Program—Pan Deng Scholars (XLYC1802005), Liaoning BaiQianWan Talents Program (LNBQW2018B0048), Natural Science Fund of Liaoning Province for Excellent Young Scholars (2019-YQ04), Key Project of Scientific Research of the Education Department of Liaoning Province (LZD201902), Foundation for Young Scholars of Liaoning University (LDQN2019007), and Natural Science Foundation of Liaoning Province of China (2020-MS-137). 


\section{Declarations}

Conflict of interest The authors certify that they have NO affiliations with or involvement in any organization or entity with any financial interest, or non-financial interest in the subject matter or materials discussed in this manuscript.

Ethical statement The authors consciously assure that this work is the authors' own original work, which has not been previously published elsewhere, the paper is not currently being considered for publication elsewhere, the paper reflects the authors' own research and analysis in a truthful and complete manner, the paper properly credits the meaningful contributions of co-authors and co-researchers, the results are appropriately placed in the context of prior and existing research, all sources used are properly disclosed (correct citation), and all authors have been personally and actively involved in substantial work leading to the paper, and will take public responsibility for its content.

Open Access This article is licensed under a Creative Commons Attribution 4.0 International License, which permits use, sharing, adaptation, distribution and reproduction in any medium or format, as long as you give appropriate credit to the original author(s) and the source, provide a link to the Creative Commons licence, and indicate if changes were made. The images or other third party material in this article are included in the article's Creative Commons licence, unless indicated otherwise in a credit line to the material. If material is not included in the article's Creative Commons licence and your intended use is not permitted by statutory regulation or exceeds the permitted use, you will need to obtain permission directly from the copyright holder. To view a copy of this licence, visit http://creativecommons.org/licenses/by/4.0/.

\section{References}

1. Crabtree, W., Dresselhaus, M.S., Buchanan, M.V.: The hydrogen economy. Phys. Today 57, 39-44 (2004). https://doi.org/10. 1063/1.1878333

2. Nocera, D.G.: The artificial leaf. Acc. Chem. Res. 45, 767-776 (2012). https://doi.org/10.1021/ar2003013

3. Canfield, D.E., Glazer, A.N., Falkowski, P.G.: The evolution and future of earth's nitrogen cycle. Science 330, 192-196 (2010). https://doi.org/10.1126/science.1186120

4. Wang, L., Xia, M., Wang, H., Huang, K., Qian, C., Maravelias, C.T., Ozin, G.A.: Greening ammonia toward the solar ammonia refinery. Joule 2, 1055-1074 (2018). https://doi.org/10.1016/j. joule.2018.04.017

5. Li, Y., Wang, H., Priest, C., Li, S., Xu, P., Wu, G.: Advanced electrocatalysis for energy and environmental sustainability via water and nitrogen reactions. Adv. Mater. 32, 2000381 (2020). https://doi.org/10.1002/adma.202000381

6. Lv, X.-W., Weng, C.-C., Yuan, Z.-Y.: Ambient ammonia electrosynthesis: current status, challenges, and perspectives. Chemsuschem 13, 3061-3078 (2020). https://doi.org/10.1002/cssc.20200 0670

7. Cui, X., Tang, C., Zhang, Q.: A review of electrocatalytic reduction of dinitrogen to ammonia under ambient conditions. Adv. Energy Mater. 8, 1800369 (2018). https://doi.org/10.1002/aenm. 201800369

8. Yang, C., Zhu, Y., Liu, J., Qin, Y., Wang, H., Liu, H., Chen, Y., Zhang, Z., Hu, W.: Defect engineering for electrochemical nitrogen reduction reaction to ammonia. Nano Energy 77, 105126 (2020). https://doi.org/10.1016/j.nanoen.2020.105126
9. Wen, L., Ren, C., Zou, Y., Lin, W., Ding, K.: Why it is S-rich around Mo atom in the nitrogenase: a DFT investigation. Appl. Surf. Sci. 534, 147595 (2020). https://doi.org/10.1016/j.apsusc. 2020.147595

10. Zhang, L., Ji, X., Ren, X., Ma, Y., Shi, X., Tian, Z., Asiri, A.M., Chen, L., Tang, B., Sun, X.: Electrochemical ammonia synthesis via nitrogen reduction reaction on a $\mathrm{MoS}_{2}$ Catalyst: theoretical and experimental studies. Adv. Mater. 30, 1800191 (2018). https:// doi.org/10.1002/adma.201800191

11. Li, X., Li, T., Ma, Y., Wei, Q., Qiu, W., Guo, H., Shi, X., Zhang, P., Asiri, A.M., Chen, L., Tang, B., Sun, X.: Boosted electrocatalytic $\mathrm{N}_{2}$ reduction to $\mathrm{NH}_{3}$ by defect-rich $\mathrm{MoS}_{2}$ nanoflower. Adv. Energy Mater. 8, 1801357 (2018). https://doi.org/10.1002/aenm. 201801357

12. Li, X., Ren, X., Liu, X., Zhao, J., Sun, X., Zhang, Y., Kuang, X., Yan, T., Wei, Q., Wu, D.: A MoS 2 nanosheet-reduced graphene oxide hybrid: an efficient electrocatalyst for electrocatalytic $\mathrm{N}_{2}$ reduction to $\mathrm{NH}_{3}$ under ambient conditions. J. Mater. Chem. A 7, 2524-2528 (2019). https://doi.org/10.1039/C8TA10433F

13. Zeng, L., Chen, S., van der Zalm, J., Li, X., Chen, A.: Sulfur vacancy-rich $\mathrm{N}$-doped $\mathrm{MoS}_{2}$ nanoflowers for highly boosting electrocatalytic $\mathrm{N}_{2}$ fixation to $\mathrm{NH}_{3}$ under ambient conditions. Chem. Commun. 55, 7386-7389 (2019). https://doi.org/10.1039/c9cc0 2607

14. Xu, T., Ma, D., Li, T., Yue, L., Luo, Y., Lu, S., Shi, X., Asiri, A.M., Yang, C., Sun, X.: Enhanced electrocatalytic $\mathrm{N}_{2}$-to- $\mathrm{NH}_{3}$ fixation by $\mathrm{ZrS}_{2}$ nanofibers with a sulfur vacancy. Chem. Commun. 56, 14031-14034 (2020). https://doi.org/10.1039/d0cc05917

15. Zhao, X., Lan, X., Yu, D., Fu, H., Liu, Z., Mu, T.: Deep eutecticsolvothermal synthesis of nanostructured $\mathrm{Fe}_{3} \mathrm{~S}_{4}$ for electrochemical $\mathrm{N}_{2}$ fixation under ambient conditions. Chem. Commun. 54, 13010-13013 (2018). https://doi.org/10.1039/C8CC08045C

16. Xiong, W., Guo, Z., Zhao, S., Wang, Q., Xu, Q., Wang, X.: Facile, cost-effective plasma synthesis of self-supportive $\mathrm{FeS}_{\mathrm{x}}$ on $\mathrm{Fe}$ foam for efficient electrochemical reduction of $\mathrm{N}_{2}$ under ambient conditions. J. Mater. Chem. A 7, 19977-19983 (2019). https://doi.org/ 10.1039/C9TA07790A

17. Wei, P., Xie, H., Zhu, X., Zhao, R., Ji, L., Tong, X., Luo, Y., Cui, G., Wang, Z., Sun, X.: $\operatorname{CoS}_{2}$ nanoparticles-embedded $\mathrm{N}$-doped carbon nanobox derived from ZIF-67 for electrocatalytic $\mathrm{N}_{2}$-to- $\mathrm{NH}_{3}$ fixation under ambient conditions. ACS Sustain. Chem. Eng. 8, 29-33 (2020). https://doi.org/10.1021/acssuschem eng.9b06272

18. Chen, P., Zhang, N., Wang, S., Zhou, T., Tong, Y., Ao, C., Yan, W., Zhang, L., Chu, W., Wu, C., Xie, Y.: Interfacial engineering of cobalt sulfide/graphene hybrids for highly efficient ammonia electrosynthesis. Proc. Natl. Acad. Sci. USA 116, 6635-6640 (2019). https://doi.org/10.1073/pnas.1817881116

19. Liu, Y., Chen, X., Yu, J., Ding, B.: Carbon-nanoplated $\mathrm{CoS} @ \mathrm{TiO}_{2}$ nanofibrous membrane: an interface-engineered heterojunction for high-efficiency electrocatalytic nitrogen reduction. Angew. Chem. Int. Ed. 131, 19079-19083 (2019). https://doi.org/10.1002/ange. 201912733

20. Huang, H., Li, F., Xue, Q., Zhang, Y., Yin, S., Chen, Y.: Salt-templated construction of ultrathin cobalt doped iron thiophosphite nanosheets toward electrochemical ammonia synthesis. Small 15, 1903500 (2019). https://doi.org/10.1002/smll.201903500

21. Wu, X., Wang, Z., Han, Y., Zhang, D., Wang, M., Li, H., Zhao, H., Pan, Y., Lai, J., Wang, L.: Chemically coupled NiCoS/C nanocages as efficient electrocatalysts for nitrogen reduction reactions. J. Mater. Chem. A 8, 543-547 (2020). https://doi.org/10.1039/ C9TA10142J

22. Zhang, D., Gokce, B., Barcikowski, S.: Laser synthesis and processing of colloids: fundamentals and applications. Chem. Rev. 117, 3990-4103 (2017). https://doi.org/10.1021/acs.chemrev. $6 \mathrm{~b} 00468$

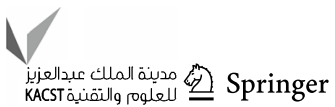


23. Zhao, Y., Jin, B., Vasileff, A., Shi, B., Jiao, Y., Qiao, S.-Z.: The ampoule method: a pathway towards controllable synthesis of electrocatalysts for water electrolysis. Chem. Eur. J. 26, 38983905 (2020). https://doi.org/10.1002/chem.201903060

24. Zhao, Y., Jin, B., Zheng, Y., Jin, H., Jiao, Y., Qiao, S.Z.: Charge state manipulation of cobalt selenide catalyst for overall seawater electrolysis. Adv. Energy Mater. 8, 1801926 (2018). https://doi. org/10.1002/aenm.201801926

25. Zhao, Y., Jin, B., Vasileff, A., Jiao, Y., Qiao, S.Z.: Interfacial nickel nitride/sulfide as a bifunctional electrode for highly efficient overall water/seawater electrolysis. J. Mater. Chem. A 7, 8117-8121 (2019). https://doi.org/10.1039/C9TA01903K

26. Zhao, Y., Ling, T., Chen, S., Jin, B., Vasileff, A., Jiao, Y., Song, L., Luo, J., Qiao, S.Z.: Non-metal single-iodine-atom electrocatalysts for the hydrogen evolution reaction. Angew. Chem. Int. Ed. 58, 12252-12257 (2019). https://doi.org/10.1002/anie.201905554

27. Zhao, Y., Jin, B., Vasileff, A., Jiao, Y., Qiao, S.Z.: Contemporaneous oxidation state manipulation to accelerate intermediate desorption for overall water electrolysis. Chem. Commun. 55, 8313-8316 (2019). https://doi.org/10.1039/C9CC04231H

28. Feng, D., Zhang, X., Sun, Y., Ma, T.: Surface-defective $\mathrm{FeS}_{2}$ for electrochemical $\mathrm{NH}_{3}$ production under ambient conditions. Nano
Mater. Sci. 2, 132-139 (2020). https://doi.org/10.1016/j.nanoms. 2019.07.002

29. Yu, B., Li, H., White, J., Donne, S., Yi, J., Xi, S., Fu, Y., Henkelman, G., Yu, H., Chen, Z., Ma, T.: Tuning the catalytic preference of ruthenium catalysts for nitrogen reduction by atomic dispersion. Adv. Funct. Mater. 30(6), 1905665 (2019). https://doi.org/ 10.1002/adfm.201905665

30. Sun, Y., Deng, Z., Song, X., Li, H., Huang, Z., Zhao, Q., Feng, D., Zhang, W., Liu, Z., Ma, T.: Bismuth-based free-standing electrodes for ambient-condition ammonia production in neutral media. Nano-Micro Lett. 12, 133 (2020). https://doi.org/10.1007/ s40820-020-00444-y

31. Barreca, D., Casparotto, A., Maragno, C., Tondello, E., Spalding, T.R.: Analysis of nanocrystalline $\mathrm{ZnS}$ thin films by XPS. Surf. Sci. Spectra 9, 54-61 (2003). https://doi.org/10.1116/11.20030 117

32. Tabet, N., Faiz, M., Al-Oterbi, A.: XPS study of nitrogenimplanted $\mathrm{ZnO}$ thin films obtained by DC-Magnetron reactive plasma. J. Electron Spectrosc. Relat. Phenom. 163, 15-18 (2008). https://doi.org/10.1016/j.elspec.2007.11.003

\section{Authors and Affiliations}

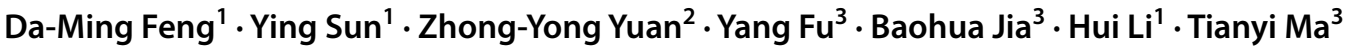

Hui Li

lihuichemical@gmail.com

$\triangle$ Tianyi Ma

tianyima@swin.edu.au

1 Institute of Clean Energy Chemistry, Key Laboratory for Green Synthesis and Preparative Chemistry of Advanced Materials, College of Chemistry, Liaoning University, Shenyang 110036, China
2 Key Laboratory of Advanced Energy Materials Chemistry (Ministry of Education), Nankai University, Tianjin 300071, China

3 Centre for Translational Atomaterials, Faculty of Science, Engineering and Technology, Swinburne University of Technology, Hawthorn, VIC 3122, Australia 